\title{
The interface between formal and informal support in advanced old age: a ten-year study
}

\author{
By Franca Armi, Edith Guilley E Christian J. Lalive d'Epinay
}

\begin{abstract}
The aim of this paper is to investigate the interface between the formal and informal support provided to very old people against a background of increasing need for care and a decreasing number of potential informal caregivers. We used a sample of 323 community-dwelling octogenarians participating in the Swiss Interdisciplinary Longitudinal Study on the Oldest Old (SWILSOO) $(n=1441$ interviews). Descriptive analyses and a multilevel model were used to test whether formal and informal services complemented or substituted one another. The study revealed that the amount of informal services increased significantly as the frequency of formal aid increased, indicating that the two networks were complementary in the majority of the cases. In $21.2 \%$ of the cases, the formal network partly substituted the informal network (as an adjustment) and only in $6.4 \%$ of the cases did the informal support end after the formal support had increased (radical substitution). The concern that the introduction of formal services may curb the readiness of relatives and friends to provide care is thus unfounded.
\end{abstract}

Keywords: social support, longitudinal study, oldest old, formal care, informal care.

Franca Armi, Edith Guilley \& Christian J. Lalive d'Epinay, Center for Interdisciplinary Gerontology (CIG), University of Geneva, Switzerland. 
International Journal of Ageing and Later Life

\section{Background}

Since the 1980s, the relationship between formal and informal support networks has been widely studied. Nevertheless, how the two networks coexist continues to present researchers with numerous conceptual challenges. Various theoretical models have been devised to describe the interface between formal and informal services (cf. Davey \& Patsios 1999; Travis 1995; Vézina \& Membrado 2005). The substitution model hypothesizes that formal services replace part of the support provided by informal networks. It thus implies a negative correlation between the evolution of formal and informal services. According to the substitution model, the introduction of formal services may prompt relatives and friends to curtail their informal caregiving efforts and curb their feeling of responsibility for care. In contrast to the substitution model, the complementary and supplemental models hypothesize that the introduction of formal services does not induce a significant drop in the amount of services provided by the informal networks. By applying a task-oriented approach, the latter two models can be differentiated: in a complementary arrangement, one given task is performed by both networks while in a supplemental arrangement, some tasks are performed by both networks while others are specifically performed by one or other network. Lastly, the hierarchical compensatory model details older adults' hierarchical preference for assistance. Elderly people are more likely to look first to spouses, next to adult children, then to other relatives and friends, and finally to formal services for support. The last-mentioned generally come into play solely when no informal network is available (Cantor 1979).

Previous studies on the relationship between formal and informal networks relied mainly on cross-sectional data (e.g. Davey \& Patsios 1999; Penning 2002; Sundström et al. 2006). While cross-sectional studies are very informative with respect to care utilisation differences between individuals, only longitudinal data can throw light on the effect of changes in the formal network on the amount of informal social support. In order to study the interface between formal and informal networks, longitudinal data are thus required. Furthermore, the previous studies mentioned above were essentially devoted to the younger elderly. For this population, empirical evidence of the substitution hypothesis was seldom documented (cf. for instance, Logan \& Spitze 1994). The substitution was found to occur 
only over the short term (Tennstedt et al. 1996), and therefore tended to be temporary. To our knowledge, no study has examined the formalinformal interface specifically among a very old population. This population needs more assistance with personal care than the younger elderly, and therefore lends itself to a study of the relationship between formal and informal networks. Cases of substitution may be more frequent in a very old population when contemporary caregivers are also very old and are likely to have assumed the role of caregiver for a long time.

\section{Aim}

Our objective was to investigate the formal-informal interface in the context of an increasing need for care and a decreasing number of potential informal carers, within a population of Swiss octogenarians monitored over a period of ten years. In other words, we wanted to see how help from informal networks evolves when the utilisation of formal services increases. We tested the following three models: (1) complementary: the increase in formal support is associated with an increase in, or stability of, informal support; (2) substitution as an adjustment in the informal network: the increase in formal support is associated with a relative decline in informal aid; and (3) radical substitution: the increase in formal support is associated with the disappearance of informal aid. It was impossible to differentiate the complementary model from the supplemental model because we did not ask who provided help with each of the tasks considered.

\section{Methods}

\section{Participants}

The Swiss Interdisciplinary Longitudinal Study on the Oldest Old (SWILSOO) is a study covering the fields of sociology, social medicine, social and cognitive psychology, and econometrics (e.g. Guilley et al. 2005). The initial sample comprised 340 community-dwelling persons aged between 80 and 84 years. Participants were randomly selected from the lists of octogenarians of the State Offices of Population living in the canton of Geneva (an urban area) and in the central Valais (a semi-rural 
International Journal of Ageing and Later Life

area) in Switzerland. The sampling frame was stratified at baseline by geographical area and gender. Participants were interviewed up to nine times (i.e. nine waves) on an approximately yearly basis (every 12 or 18 months) over a period of ten years (from 1994 to 2004). Analyses were limited to the 323 participants who provided sufficient data for computation (see Table 1 for the number of participants at each wave). The octogenarians answered a trained interviewer, either in person or, if unable to do so, through a proxy (the proportion of proxy reports ranged from 8.7 to $26.2 \%$ in the course of the study period). After the ten-year period, there were $59(18.3 \%)$ surviving participants (of whom 45 were still community-dwellers) and $37(11.4 \%)$ surviving dropouts, while 227 (70.3\%) of the original participants had died.

\section{Measures}

We defined informal support as the help received from family members and friends and/or acquaintances, excluding help received from household members. Two series of questions assessed the frequency of six instrumental aids ${ }^{1}$ that the very old person received from such sources. A choice of four possible answers was given: 'never', 'rarely', 'sometimes', and 'often'. All community-dwelling participants were questioned. For the formal network, which is provided by subsidized or fee-paid professionals, a series of six types of service ${ }^{2}$ was put to all community-dwelling

1 Performing household tasks; bringing or preparing meals; doing the shopping; doing repairs, odd jobs and gardening; help with completing income tax returns and insurance claims; help with toilet activies.

2 Care from a nurse; help from a household/family helper (with everyday tasks such as housework, washing, shopping, preparing meals, and going to see the doctor); counselling from a social worker (e.g. to help complete formalities, fill in forms, apply for aid from other agencies, manage his/her money); homedelivered meals; day-care or voluntary centres; help from an association. (Various associations such as Pro Senectute offer services to older people. The associations' staff and volunteers deliver such services as social counselling, the provision of practical information, and assistance in arranging home help, and in addition make available a range of suitable activities.) The services most used were household/family helper and care from a nurse. 
Interface Between Formal and Informal Support

Table 1. Number of interviews with the community-dwelling participants across the nine waves of SWILSOO

\begin{tabular}{|c|c|c|c|c|c|c|c|c|c|c|}
\hline & \multicolumn{9}{|c|}{ Waves } & \multirow[b]{2}{*}{ Total } \\
\hline & 1 & 2 & 3 & 4 & 5 & 6 & 7 & 8 & 9 & \\
\hline Self-respondents & 295 & 224 & 190 & 162 & 124 & 99 & 75 & 51 & 42 & 1262 \\
\hline Proxy respondents & 28 & 27 & 29 & 28 & 29 & 16 & 10 & 9 & 3 & 176 \\
\hline Total & 323 & 251 & 219 & 190 & 153 & 115 & 85 & 60 & 45 & 1441 \\
\hline
\end{tabular}

participants, with six possible answers: 'never', 'rarely', 'every month', 'every two weeks', 'once a week', 'every day'. Those questions enabled us to construct frequency scores for each of the three networks (family, friends and formal) by averaging out the different answers given. The mean frequency scores for family members and for friends and/or acquaintances were merged to obtain a score for the non-household informal services.

The formal-informal care interface was analyzed with controls of potential confounding factors such as socio-demographic variables, need factors, and household and informal network composition.

- The socio-demographic variables used were age, gender, geographical area (urban or semi-rural area) and socio-economic status (working-class or middle/upper-class). Socio-economic status was assessed as a composite of education, income and socio-occupational categories.

- Need factors were assessed by means of a three-tier health status: ADL-dependent, ADL-independent frail, and robust. A participant was considered ADL-dependent if he/she was unable to perform alone at least one of five activities of daily living (washing, dressing and undressing, eating, rising from and going to bed, and moving from one room to another) (cf. Katz et al. 1963). Participants having no ADL incapacities but suffering from two or more deficiencies in five health domains (sensoriality, mobility, memory, energy and physical ailments) were considered ADL-independent frail; participants without ADL incapacities and with less than two deficiencies in the above-mentioned health domains were considered robust (for more details, see Guilley et al. 2008). SWILSOO publications had 
International Journal of Ageing and Later Life

already demonstrated that each health status was associated with a specific 'everyday life-world' (specific well-being, social activities and relationships as well as different risks of adverse health outcomes) (Lalive d'Epinay \& Guilley 2006).

- Although this paper deals with the services provided by nonhousehold caregivers, the household composition (living or not with a cohabitant) was taken as a control in the analysis of the formal-informal care interface.

- Finally, the composition of the informal network was assessed by means of standard questions about the existence of living siblings, descendants (children, grandchildren or great grandchildren), and close friends.

\section{Plan of Analysis}

Before analyzing the interface between the two networks, we assessed how the need for care and the composition of the informal network evolved over the study period. Multilevel analyses were used to assess the relationship between (a) the need for care or the composition of the informal network and (b) the age of participants. The regression coefficients $(\beta)$ indicate whether the need for care or the percentage of persons having potential caregivers increases $(\beta>0)$, decreases $(\beta<0)$ or stays the same ( $\beta$ not significantly different from zero) across the study. Analyses were performed on 323 participants (representing 1441 interviews across the nine-wave follow-up). Multilevel analyses were developed for the purpose of analyzing data with multilevel sets (e.g. repeated measures within an individual). They allow the use of repeated measures where both the number of interviews per participant and the time intervals between interviews vary. Furthermore, multilevel analyses can tolerate an incomplete data set because they use all available data (instead of restricting the analysis to individuals who participated in the nine waves of the study) and therefore limit the selectivity effects (Raudenbush \& Bryk 2002; Snijders \& Bosker 1999).

Subsequently, we tested whether formal and informal networks substitute one another or are complementary. We evaluated the relationship between the frequencies of formal and informal care using a multilevel analysis on 1441 interviews controlled by socio-demographic variables, 
need factors and the composition of informal networks. The substitution model implies a negative relationship between formal and informal services, while an insignificant or positive relationship is expected in the complementary model. Age (centered on its grand mean), household composition, variables on the presence of an informal network, health status and the frequency of formal care were included as level-1 timevarying predictors, and gender, socio-economic status, and geographical area as level-2 time-invariant predictors. Multilevel models were fitted by the method of restricted maximum likelihood using HLM version 6 (Raudenbush et al. 2004) and results were reported with a robust estimation of the standard errors.

Work carried out previously was useful in assessing the relationship between the amount of informal and formal supports with control of variables, but it provided only general information on the formal-informal care interface. To clarify this interface we adopted a different approach: we examined the proportion of interviews (one individual can be represented more than once) whose pattern of support was consistent with each theoretical model of formal-informal interface. To assess the exact percentage of cases falling into the categories of complementary (increase or stability of the informal network), substitution as an adjustment or radical substitution, we used the following analysis. When the frequency of formal services increased at two successive waves (i.e. periods between waves $1-2,2-3$, and so on), we counted the number of cases for which the frequency of informal services simultaneously (a) increased, (b) stayed the same, (c) decreased, or (d) ceased. This analysis was limited to 236 interviews (those for which one of the two networks was lacking and those presenting no increase in formal help were thus excluded).

\section{Results}

Table 2 reports the characteristics of the sample and Table 3 their evolution over the ten-year period. While $60.8 \%$ of the participants lived with a cohabitant at baseline, this percentage fell during the study, illustrating the growing number of single people in need of non-household care. The vast majority of very old participants had the benefit of a potential informal network $(97.5 \%$ at baseline had at least one potential caregiver: a 
International Journal of Ageing and Later Life

Table 2. Characteristics at baseline $(n=323)$

\begin{tabular}{lc}
\hline & $n(\%)^{*}$ \\
\hline $\begin{array}{l}\text { Household composition } \\
\text { Lives with a cohabitant }\end{array}$ & $194(60.8)$ \\
Potential informal network & \\
Has at least one descendant & $263(81.4)$ \\
Has at least one sibling & $227(70.7)$ \\
Has at least one close friend ${ }^{* *}$ & $213(73.2)$ \\
Need of care & \\
Is robust & $126(39.1)$ \\
Is ADL-independent frail & $166(51.6)$ \\
Is ADL-dependent & $30(9.3)$ \\
\hline
\end{tabular}

*Percentages are given for subjects without missing values.

**Only self-respondents included.

descendant, a sibling or a close friend). However, the network composed of siblings and friends, who were likely to be the participants' contemporaries, shrank over the period. In parallel to those changes, the need for care increased. At baseline, only $9.3 \%$ of the persons interviewed were

Table 3. Evolution across the nine SWILSOO waves ( $n=1441$ interviews)

\begin{tabular}{lc}
\hline & $\begin{array}{c}\text { Evolution across the nine } \\
\text { waves }^{\dagger}: \beta(S E)\end{array}$ \\
\hline $\begin{array}{l}\text { Household composition } \\
\text { Lives with a cohabitant }\end{array}$ & $-0.05(0.02)^{* *}$ \\
Potential informal network & $0.01(0.01)$ \\
Has at least one descendant & $-0.09(0.02)^{* * *}$ \\
Has at least one sibling & $-0.07(0.02)^{* *}$ \\
Has at least one close friend $t$ & \\
Need of care & $-0.12(0.02)^{* * *}$ \\
Robust versus ADL-independent frail & $0.19(0.03)^{* * *}$ \\
DL-dependent versus ADL-independent frail &
\end{tabular}

${ }^{*} p<0.05,{ }^{* *} p<0.01,{ }^{* * *} p<0.001$.

${ }^{\dagger} \beta$ : unstandardized regression coefficient between the characteristics listed and the age of participants estimated by multilevel analyses.

Only self-respondents included. 
ADL-dependent, 51.6\% were ADL-independent frail, while 39.1\% were still robust in spite of their age. During the study period, the proportion of robust individuals fell sharply while that of ADL-dependent subjects rose.

Table 4 shows how the help provided by non-household informal services evolved in relation to changes in formal help, with controls for socio-demographic variables, need factors, and household and informal network composition. As could be expected, having one or more descendants substantially increased the frequency of the informal services. Persons living with a cohabitant - who, when present, is often the principal caregiver - received fewer services from the other caregivers. Irrespective of their living arrangements, women were better provided with informal care.

Table 4. Frequency of non-household informal services as a function of the frequency of formal care and controls: multilevel analysis $(n=1441$ interviews)

Unstandardized regression coefficient $\beta$ (SE)

Socio-demographic factors

Age (years)

$0.00(0.00)$

Gender (woman)

Socio-economic status (middle/upper-class)

$0.06(0.03)^{*}$

Geographical area (urban)

Household composition

Lives with a cohabitant

$-0.10(0.02)^{* * *}$

Potential informal network

Has at least one descendant

$-0.10(0.03)^{* *}$

Has at least one sibling

$.11(0.02)^{* * *}$

Has at least one close friend

$0.01(0.02)$

Need of care

Robust versus ADL-independent frail

$0.00(0.01)$

ADL-dependent versus ADL-independent frail

$-0.02(0.02)$

Age*ADL-dependent

Formal network

Frequency of formal care

$0.08(0.02)^{* * *}$

${ }^{*} p<0.05,{ }^{* *} p<0.01,{ }^{* * *} p<0.001$. 
International Journal of Ageing and Later Life

The region of residence and the socio-economic status were also determining factors in receiving informal services: persons living in the urban area and persons in the middle and upper socio-economic groups received fewer services. ADL-dependent participants received more informal services than ADL-independent frail persons, who received an amount of services similar to robust persons (previous work has shown that, without controlling for frequency of formal care, persons having different health statuses received different amounts of help, at least among younger old participants). In contrast, the frequency of aid offered by the informal network was the same for both ADL-independent frail and robust persons, at a fixed frequency of formal care. The results also showed that on average the amount of informal services rose in line with increasing frequency of formal aid, thus lending weight to the complementary model. For the oldest ADL-dependent participants, the relationship between formal and informal networks remained positive but was less marked.

As the above analysis yielded only general information on the formalinformal care interface, we assessed the proportion of cases whose pattern of support was consistent with the complementary and substitution (radical or as an adjustment) models. Table 5 presents the changes in the frequency of informal services between two successive waves when the frequency of formal services increased. A greater use of formal services was associated with increased informal care in $47.0 \%$ of the interviews, with unchanged intensity of informal care in $25.4 \%$ of the interviews, with less extensive informal care in $21.2 \%$ of the interviews, and with cessation

Table 5. Changes in the frequency of informal services between two successive waves when the frequency of formal services increases, number of interviews (\%)

\begin{tabular}{llr}
\hline Changes in the frequency of informal & Complementary & \\
services between two successive waves & Increase & $111(47.0)$ \\
& $\begin{array}{l}\text { No change } \\
\text { Substitution as an adjustment }\end{array}$ & $60(25.4)$ \\
& $\begin{array}{l}\text { Decrease } \\
\text { Radical substitution } \\
\text { Cessation }\end{array}$ & $50(21.2)$ \\
& $15(6.4)$ \\
\hline
\end{tabular}

'Successive waves' means periods between waves 1-2, 2-3, and so on. 
Interface Between Formal and Informal Support

of informal services in $6.4 \%$ of the interviews. The two networks were hence complementary in $72.4 \%$ of the interviews, and the formal network substituted (radically or as an adjustment) the informal network in $27.6 \%$ of the interviews.

\section{Discussion}

This study, based on data obtained by monitoring a sample of octogenarians over a period of 10 years, was mainly motivated by the following question: in parallel to an increasing need for help and a dwindling number of potential informal helpers, does the help provided by formal services partly replace the informal support? We found that formal and informal supports were on the whole positively related, thus lending weight to the complementary model. By testing three models (complementary, substitution as an adjustment, and radical substitution), we found that the formal and informal networks were complementary in the majority of cases $(72.4 \%)$. Our results are in harmony with most previous research based on younger old persons, which demonstrated that formal and informal networks were complementary resources (e.g. Davey \& Patsios 1999; Denton 1997; Penning 2002). We showed further that additional needs were catered for by formal networks in $25.4 \%$ of the cases and by both networks in $47.0 \%$. However, the formal network substituted the informal services in $27.6 \%$ of the cases. In $21.2 \%$ of the cases, there was an adjustment and only in $6.4 \%$ of the cases was there a radical substitution. In the cases of adjustment, the reduction of the informal services was probably a sign that an elderly parent who had become more severely impaired needed professional care which could no longer be provided by the relatives. Indeed, the informal network tends to continue caring for old persons as long as it is capable of doing so, with formal networks coming into play essentially when professional skills are necessary (Armi et al. 2007). The introduction of formal networks may then lighten the task of the caregivers or redirect them to other forms of care. For the instances of radical substitution $(6.4 \%)$, two hypotheses are possible. The first would be to postulate a disengagement, which may occur in the case of caregivers for whom the help has become too burdensome. However, results from previous research indicate that the 
International Journal of Ageing and Later Life

disengagement of caregivers is a rare occurrence (e.g. Garant \& Bolduc 1990), even after the institutionalization of a dependent parent, where families continue to provide a high level of help (Cavalli 2002) or in generous welfare systems, which foster rather than undermine family solidarity (Künemund \& Rein 1999). The second hypothesis could relate to situations where a caregiver had died or had serious health problems.

We also observed the determinants of informal network use which may influence the interface between formal and informal support. Our results are consistent with previous studies which found that women and persons with a lower socio-economic status received more help from the informal network (e.g. Broese van Groenou et al. 2006; Litwin 2004). This gender effect may be explained by the fact that women receive less support from their husbands (Gurung et al. 2003), partly because they tend to outlive their husbands and thus are more likely to resort to the non-household informal network. As for the effect of socio-economic status, the relative neediness of persons in the lower-status category prompts more informal help than that given to persons of a higher socio-economic status (Broese van Groenou et al. 2006). We also found that persons living in the semi-rural area received more informal services than the city-dwellers. Indeed, in a semi-rural sociocultural context, 'being together' tends to imply the sharing of domestic chores and the exchange of services, while in an urban context it implies the sharing of a leisure activity (Lalive d'Epinay et al. 2000).

In spite of its major strengths (longitudinal design and long-term tracking of very old persons who displayed widely different health statuses), this study was limited by the lack of information on the services provided by the cohabitant, who is likely to be the primary kin caregiver. However, this limitation obviously does not concern older persons living alone, who represented half of the sample from the fifth wave onwards. For persons living with their spouse, the amount of help provided by the latter is likely to decrease with time and with advancing age. Those couples may then require more help from non-household caregivers.

\section{Conclusion}

This study showed that, in a context of increasing need for care and a declining number of potential informal caregivers, informal and formal 
networks of support for the very old were complementary in the majority of the cases. Cases of radical substitution were rare. The concern that the introduction of formal services may curb the readiness of relatives and friends to provide care is thus unfounded. Future research should examine how formal networks could share knowledge with informal networks and how the former can act to better support stressed informal caregivers, especially when the latter are also very old and have assumed the role of caregiver for a long time.

\section{Acknowledgements}

This study was supported by the Swiss National Science Foundation (SNF) (Principal Investigator Profesor Christian J. Lalive d'Epinay). We thank Ian Hamilton for his editorial assistance.

\section{Corresponding Author}

Franca Armi, Center for Interdisciplinary Gerontology (CIG) Rte de Drize 7, CH-1227 Carouge, Switzerland. Email: armif@bluewin.ch

\section{References}

Armi, F., Guilley, E. \& Lalive d'Epinay, C. (2007). Entraide et recours aux services [Mutual assistance and use of services]. In C. Lalive d'Epinay \& D. Spini (eds.) Les Années Fragiles: La Vie Au-delà des Quatre-vingts Ans [The frailty years: life beyond eighty years old] (pp. 209-246). Quebec, Canada: Les Presses de l'Université de Laval.

Broese van Groenou, M. I., Glaser, K., Tomassini, C. \& Jacobs, T. (2006). Socio-economic status differences in older people's use of informal and formal help: A comparison of four European countries. Ageing and Society 26(5): 745-766.

Cantor, M. H. (1979). Neighbours and friends, an overlooked resource in the informal support system. Research on Aging 1(4): 434-463.

Cavalli, S. (2002). Vieillards à Domicile, Vieillards en Pension: Une Comparaison [Elders at Home, Elders in a Nursing Home: A Comparison]. Lausanne: Réalités Sociales. 
International Journal of Ageing and Later Life

Davey, A. \& Patsios, D. (1999). Formal and informal community care to older adults: Comparative analysis of the United States and Great Britain. Journal of Family and Economic Issues 20(3): 271-299.

Denton, M. (1997). The linkages between informal and formal care of the elderly. Canadian Journal on Aging/La Revue Canadienne du Vieillissement 16(1): 30-50.

Garant, L. \& Bolduc, M. (1990). L'aide par les Proches: Mythes et Réalités [Help from Loved Ones: Myth and Reality]. Quebec: Direction de l'Évaluation, Ministère de la Santé et des Services Sociaux.

Guilley, E., Ghisletta, P., Armi, F., Berchtold, A., Lalive d'Epinay, C., Michel, J.-P., et al. (2008). Dynamics of frailty and ADL-dependence in a five-year longitudinal study of octogenarians. Research on Aging, 30(3): 299-317.

Guilley, E., Pin, S., Spini, D., Lalive d'Epinay, C., Herrmann, F. \& Michel, J.-P. (2005). Association between social relationships and survival of Swiss octogenarians. A five-year prospective, population-based study. Aging Clinical and Experimental Research 17(5): 419-425.

Gurung, R. A. R., Taylor, S. E. \& Seeman, T. E. (2003). Accounting for changes in social support among married older adults: Insights from the MacArthur studies of successful aging. Psychology and Aging 18(3): 487-496.

Horowitz, A. (1985). Family caregiving to the frail elderly. In M. P. Lawton and G. L. Maddox (Eds.), Annual Review of Gerontology and Geriatrics (pp. 57-71). New York: Springer.

Katz, S., Ford, A. B., Moskowitz, R. W., Jackson, B. A. \& Jaffee, M. W. (1963). Studies of illness in the aged. The index of ADL: A standardized measure of biological and psychosocial function. Journal of the American Medical Association 185(Sep 21): 94-101.

Künemund, H. \& Rein, M. (1999). There is more to receiving than needing: Theoretical arguments and empirical explorations of crowding in and crowding out. Ageing and Society 19(1): 99-121.

Lalive d'Epinay, C. \& Guilley, E. (2006). Statuts de santé et mondes de vie quotidienne des vieillards [Health statuses and everyday life-worlds of the oldest old]. Swiss Journal of Sociology 32(3): 407-427.

Lalive d'Epinay, C., Bickel, J.-F., Maystre, C. \& Vollenwyder, N. (2000). Vieillesses au Fil du Temps. 1979-1994: Une Révolution Tranquille [Old Age 
Interface Between Formal and Informal Support

Across the Years. 1979-1994: A Quiet Revolution]. Lausanne: Réalités Sociales.

Litwin, H. (2004). Social networks, ethnicity and public home-care utilisation. Ageing and Society 24(6): 921-939.

Logan, J. R. \& Spitze, G. (1994). Informal support and the use of formal services by older Americans. Journal of Gerontology: Social Sciences 49(1): S25-S34.

Penning, M. J. (2002). Hydra revisited: Substituting formal for self- and informal in-home care among older adults with disabilities. The Gerontologist 42(1): 4-16.

Raudenbush, S. W. \& Bryk, A. S. (2002). Hierarchical Linear Models. Applications and Data Analysis Methods ( $2^{\text {nd }}$ ed.). Thousand Oaks, CA: Sage.

Raudenbush, S. W., Bryk, A. S., Cheong, Y. F. \& Congdon, R. T. Jr. (2004). HLM 6: Hierarchical Linear and Nonlinear Modelling (6 $6^{\text {th }}$ ed.). Lincolnwood, IL: Scientific Software International.

Snijders, T. A. B. \& Bosker, R. J. (1999). Multilevel Analysis. An Introduction to Basic and Advanced Multilevel Modeling. London: Sage.

Sundström, G., Malmberg, B. \& Johansson, L. (2006). Balancing family and state care: neither, either or both? The case of Sweden. Ageing and Society 26(5): 767-782.

Tennstedt, S., Harrow, B. \& Crawford, S. (1996). Informal care vs. formal services: Changes in patterns of care over time. Journal of Aging and Social Policy 7(3-4): 71-91.

Travis, S. S. (1995). Families and formal networks. In R. Blieszner \& V. H. Bedford (eds.) Handbook of Aging and the Family (pp. 459-473). Westport, CT: Greenwood Press.

Vézina, A. \& Membrado, M. (2005). Un travail de négociation et de gestion des ressources [A task of negotiating and managing resources]. In S. Clément \& J.-P. Lavoie (eds.) Les Enseignements de la France et du Québec [The Lessons to be Drawn from France and Quebec] (pp. 186-243). Bonchamp-Lès-Laval: Érès. 